\title{
Examining the Reception and Impact of the Dead Sea Scrolls: Some Possibilities for Future Investigation
}

\author{
Matthew A. Collins
}

\begin{abstract}
The last sixty years afford us a remarkable, though largely unexplored, opportunity to examine the Dead Sea Scrolls from the perspective of "reception history." This article first provides an overview of what has already been done with regard to this goal and highlights the importance and timeliness of such an approach, suggesting that it is furthermore a necessary endeavor if Qumran Studies is to keep pace with developments in the wider world of Biblical Studies. It continues by outlining some possible directions for future investigation, identifying academic reception, popular reception, and processes of knowledge transfer as three main areas or categories into which such examinations could helpfully be divided. The internal processes of scrolls scholarship, the relationship between Qumran Studies and Biblical Studies, gender issues, the scrolls in literature, film, music, and art, and the role of exhibitions, documentaries, and newspapers, are all highlighted as potential areas for future research.
\end{abstract}

\section{Keywords}

Dead Sea Scrolls; reception history; impact; history of scholarship; popular culture; media; exhibitions

\section{Introduction}

More than sixty years have passed since the discovery by a Bedouin shepherd of the first "Dead Sea Scrolls," 2,000-year-old manuscripts that were set to cause excitement and controversy both throughout the academic world and within popular culture. Ever since, they have been (perceived as) shrouded in intrigue and mystery, 
and have consequently ignited public interest, thus having an impact reaching beyond simply the realms of academia. In particular, years of restricted access to the scrolls and the painfully-slow publication process, coupled with the secretive "closed-door" policy of the early editors, ensured widespread speculation as to their contents and an infamy within the wider world that remains to this day. ${ }^{1}$ Even with all of the material now freely available, and the conspiracy theorists somewhat disappointed, the scrolls continue to be a source of fascination, not simply for scholars (who see in them a window through to the late Second Temple period and its textual diversity), but for the public alike, for whom "the Dead Sea Scrolls" constitutes a cultural "buzz-phrase" signifying mystery, conspiracy, and ancient or hidden knowledge. ${ }^{2}$

The particular circumstances surrounding the modern discovery, dissemination, and appropriation of the scrolls afford us a remarkable, though largely unexplored, opportunity to examine the Dead Sea Scrolls from the perspective of "reception history." This approach has, over the past two decades, come to play an ever more important role within Biblical Studies, supplementing "classic historical questions about the conditions and circumstances of the Bible's origins" with examinations of its reception, influence, and impact. ${ }^{3}$ In addition to numerous individual studies, the creation of a number of academic centers and programs specializing in biblical reception (e.g., at Oxford, Sheffield, Bristol, Birmingham, Copenhagen, Duquesne, and Boston $)^{4}$ and the publication of reference tools such as

\footnotetext{
${ }^{1}$ For the struggle over access to the scrolls, see initially Lawrence H. Schiffman, "The Many Battles of the Scrolls," JRH 26 (2002): 157-78. For a fuller discussion, see Weston W. Fields, The Dead Sea Scrolls: A Full History (vol. 1; Leiden: Brill, 2009 [vol. 2 forthcoming]); cf. Weston W. Fields, The Dead Sea Scrolls: A Short History (Leiden: Brill, 2006).

2 So too Sidnie White Crawford: "in the popular imagination, the very name conjures up scandal, intrigue and mystery" ("The Dead Sea Scrolls: Retrospective and Prospective," Near Eastern Archaeology 65.1 [2002]: 81-86 [81]). See further, Maxine L. Grossman and Catherine M. Murphy, eds., The Dead Sea Scrolls in the Popular Imagination (= DSD 12.1; 2005).

${ }^{3}$ See the introduction to Hans-Josef Klauck et al., eds., Encyclopedia of the Bible and its Reception (vol. 1; Berlin/New York: Walter de Gruyter, 2009), ix-xi (x). Also, W. John Lyons and Jo Carruthers, An Introduction to the Reception of the Bible (London: Continuum, forthcoming).

4 "Centre for Reception History of the Bible" (University of Oxford, UK; www.crhb.org/index.html); "Centre for the Study of the Bible in the Modern World" (University of Sheffield, UK; www.shef.ac.uk/bibs/modernworld); "Centre for Christianity and Culture" (University of Bristol, UK;
} 
John F. A. Sawyer's A Concise Dictionary of the Bible and its Reception, Oxford University Press' The Oxford Handbook of the Reception History of the Bible, Sheffield Phoenix Press' forthcoming Dictionary of the Bible and Western Culture, Wiley-Blackwell's The Blackwell Companion to the Bible and Culture, and De Gruyter's mammoth Encyclopedia of the Bible and its Reception, have firmly established biblical reception as an important and significant branch of Biblical Studies. ${ }^{5}$ Interestingly, this particular perspective incorporates, of course, not only modern reception of the Bible but its influence and impact throughout the entire transmission history of the biblical texts, including the reception of those texts within the Dead Sea Scrolls. ${ }^{6}$

While this latter area may be one that scrolls scholars are more used to exploring (i.e., studies focusing on "the Bible" at Qumran), the same "reception history" perspective may be applied to Qumran Studies itself, resulting in examinations of the modern reception, influence, and impact of the Dead Sea Scrolls. An investigation of this type has the potential to map the origins and development of ideas about the scrolls and would provide valuable insights into the (often

http://www.bristol.ac.uk/thrs/research-centres/christiancentre); "Newman Research Centre for the Bible and its Reception” (Newman University College, Birmingham, UK; http:/www.newman.ac.uk/research/biblicalstudies/?pg=2027); "Centre for the Study of the Bible in Theology and Culture" (University of Copenhagen, Denmark; www.teol.ku.dk/english/dept/csbb); "Colloquium on the Reception History of the Bible" (Duquesne University, Penn., USA; http://www.duq.edu/theology/reception-history); "Luce Program in Scripture and Literary Arts" (Boston University, Mass., USA; http://www.bu.edu/luce/mission/index.html).

5 John F. A. Sawyer, A Concise Dictionary of the Bible and its Reception (Louisville: Westminster John Knox, 2009); Michael Lieb et al., eds., The Oxford Handbook of the Reception History of the Bible (Oxford: Oxford University Press, 2011); Michael J. Gilmour and Mary A. Beavis, eds., Dictionary of the Bible and Western Culture (Sheffield: Sheffield Phoenix Press, forthcoming 2011); John F. A. Sawyer, ed., The Blackwell Companion to the Bible and Culture (Oxford: Wiley-Blackwell, 2006); Hans-Josef Klauck et al., eds., Encyclopedia of the Bible and its Reception (30 vols.; Berlin/New York: Walter de Gruyter, 2009-). Also worthy of note are the Blackwell Bible Commentaries series (Oxford: Wiley-Blackwell, 2003-) and the Bible in the Modern World series (Sheffield: Sheffield Phoenix Press, 2004-), both focusing specifically on biblical reception.

${ }^{6}$ Note, for instance, the extensive number of sub-articles in the Encyclopedia of the Bible and its Reception $(E B R)$ concerning the reception, influence, and interpretation of biblical texts and themes within Second Temple and Hellenistic Judaism. 
unconscious) influences at work within scrolls scholarship. Equally, it would allow us to both track and evaluate the wider impact of the Dead Sea Scrolls, noting in particular the manner and extent of their permeation into popular culture. It is, furthermore, a necessary endeavor if Qumran Studies is to keep pace with developments in the wider world of Biblical Studies. Accordingly, this article will first provide a brief overview of what has already been done with regard to this goal, and then continue by outlining some possible directions for future investigation, setting out research objectives and highlighting potentially fruitful lines of enquiry.

\section{Examining the Influence and Impact of the Dead Sea Scrolls}

Over the past sixty or more years since the first discoveries were made, tens of thousands of books and articles have been written on the scrolls. ${ }^{7}$ As one might expect, the vast majority of these have as their focus the scrolls themselves, their content and context, and what they can tell us about the past. By contrast, the "reception history" approach takes another step backward from the primary material and focuses instead on our own responses to the scrolls and what this can tell us about ourselves. Thus, it is the reception and appropriation of the scrolls (rather than the scrolls themselves) which becomes the subject of scrutiny.

Although most studies concerning the scrolls belong to the former "traditional" category, there are a small but growing number which do indeed reflect

\footnotetext{
${ }^{7}$ For 1948 to 1957, see William S. LaSor, Bibliography of the Dead Sea Scrolls, 1948-1957 (Pasadena: Fuller Theological Seminary, 1958). For 1958 to 1969, see Bastiaan Jongeling, A Classified Bibliography of the Finds in the Desert of Judah, 1958-1969 (STDJ 7; Leiden: Brill, 1971). For 1970 to 1995, see Florentino García Martínez and Donald W. Parry, A Bibliography of the Finds in the Desert of Judah, 1970-95 (STDJ 19; Leiden: Brill, 1996). For 1995 to 2000, see Avital Pinnick, The Orion Center Bibliography of the Dead Sea Scrolls (1995-2000) (STDJ 41; Leiden: Brill, 2001). For 2000 to 2006, see Ruth A. Clements and Nadav Sharon, The Orion Center Bibliography of the Dead Sea Scrolls and Associated Literature (2000-2006) (STDJ 71; Leiden: Brill, 2007). For subsequent works (covering 1995 to present), see the online bibliography at the Orion Center (http://orion.mscc.huji.ac.il/). Cf. Hartmut Stegemann, "Qumran Challenges for the Next Century," in The Dead Sea Scrolls: Fifty Years After Their Discovery, 1947-1997 (ed. L. H. Schiffman, E. Tov, and J. C. VanderKam; Jerusalem: Israel Exploration Society, 2000), 944-50 (944); E. Tov, "Five Decades of Discoveries, Editions, and Research," in The Dead Sea Scrolls: Fifty Years After Their Discovery, 1947-1997 (ed. L. H. Schiffman, E. Tov, and J. C. VanderKam; Jerusalem: Israel Exploration Society, 2000), 951-60.
} 
the latter "scrolls scholars once-removed" perspective. For instance, Edna UllmannMargalit's book, Out of the Cave: A Philosophical Inquiry into the Dead Sea Scrolls Research, takes as its subject matter, in her own words, "not the scrolls but the study of the scrolls; ... research about scrolls research." and maintenance of the Qumran-Essene hypothesis from the perspective of scientific theory formation in general, assessing the relationship and interaction between competitive theories within Qumran Studies and the development of a "default" position, thus shedding light upon the inner workings and dynamics of scrolls scholarship itself. ${ }^{9}$

Further examples might include those works which attempt to provide a rather reflective history of scrolls scholarship, simultaneously offering both a historical account of events and exploring the rationale and motivations which lay behind them. Here we might mention Jason Kalman and Jaqueline S. du Toit's recent volume, Canada's Big Biblical Bargain: How McGill University bought the Dead Sea Scrolls, and Weston W. Fields' two-volume work, The Dead Sea Scrolls: A Full History (of which the first volume has already appeared), both of which record the relevant "oral history" (the result of interviews with those who were involved with the discovery and publication of the scrolls) and engage in archival work, uncovering and presenting the "unofficial" written records pertaining to their impact upon the scholarly world (e.g., in the form of "personal letters and papers" made available to the authors). ${ }^{10}$ As Fields observes, "there is frequently a skewed view of who made what important decisions, or took significant actions, even of when, and why."11

Edna Ullmann-Margalit, Out of the Cave: A Philosophical Inquiry into the Dead Sea Scrolls Research (Cambridge, Mass.: Harvard University Press, 2006), 17 (my italics).

${ }^{9}$ Also, Edna Ullmann-Margalit, "Writings, Ruins and Their Reading: The Dead Sea Discoveries as a Case Study in Theory Formation and Scientific Interpretation,” Social Research 65 (1998): 839-70; Edna Ullmann-Margalit, "Spotlight on Scroll Scholars: Dissecting the Qumran-Essene Hypothesis," BAR 34.2 (2008): 63-67.

${ }^{10}$ Jason Kalman and Jaqueline S. du Toit, Canada's Big Biblical Bargain: How McGill University bought the Dead Sea Scrolls (Montreal: McGill-Queens University Press, 2010); cf. Jaqueline S. du Toit and Jason Kalman, "Great Scott! The Dead Sea Scrolls, McGill University, and the Canadian Media," DSD 12.1 (2005): 6-23. Fields, The Dead Sea Scrolls: A Full History; cf. Fields, The Dead Sea Scrolls: A Short History, 9-13. See also, Jason Kalman, "Optimistic, Even with the Negatives: The 
In a somewhat related manner, a few studies have already been made which attempt to utilize the checkered history of Dead Sea Scrolls scholarship in order to address the more general issue of copyright and intellectual property in modern academia. In particular, David Nimmer's Copyright in the Dead Sea Scrolls: Authorship and Originality, Raphael Israeli's Piracy in Qumran, and Timothy H. Lim, Hector L. MacQueen, and Calum M. Carmichael's edited volume, On Scrolls, Artefacts and Intellectual Property, all have as their focus not the scrolls themselves but the influence and impact they have had upon our society. ${ }^{12}$ Specifically, the ways in which, in the light of the Qimron v. Shanks copyright case, their discovery has had an effect reaching beyond the world of Biblical or Jewish Studies alone, and has come so far as to influence legal discussions and the world of copyright law, forcing us to address new questions about intellectual property in relation to the study and reconstruction of ancient texts. ${ }^{13}$

Another area which has been explored is, in contrast to the reception of the Bible within the scrolls (mentioned above), instead the ways in which our readings of the scrolls have come to alter our readings of the Bible itself. That is to say, not the historical-literary influence of the biblical texts upon the scrolls, but, in the other direction, the influence of the scrolls upon our approach to the Bible. This is perhaps closer in many ways to traditional Qumran Studies yet nevertheless indicative of an approach focused specifically upon the reception and influence of the scrolls. Here one might mention, by way of example, George J. Brooke's article "The Qumran Scrolls and the Demise of the Distinction between Higher and Lower Criticism," Stephen C. Daley's “Textual Influence of the Qumran Scrolls on English Bible Hebrew Union College-Jewish Institute of Religion and the Dead Sea Scrolls, 1948-1993," American Jewish Archives Journal 61.1 (2009): 1-114.

${ }^{11}$ Fields, The Dead Sea Scrolls: A Full History, 1:17.

12 David Nimmer, Copyright in the Dead Sea Scrolls: Authorship and Originality (Houston Law Review 38.1; 2001); Raphael Israeli, Piracy in Qumran: The Battle Over the Scrolls of the Pre-Christ Era (New Brunswick: Transaction Publishers, 2008); Timothy H. Lim, Hector L. MacQueen, and Calum M. Carmichael, eds., On Scrolls, Artefacts and Intellectual Property (JSPS 38; Sheffield: Sheffield Academic Press, 2001).

${ }^{13}$ For Qimron v. Shanks, see Nimmer, Copyright in the Dead Sea Scrolls, 50-82, and Lim, MacQueen, and Carmichael, On Scrolls, Artefacts and Intellectual Property, 231-58. A more general discussion of the case is provided in Israeli, Piracy in Qumran. 
Versions," James A. Sanders' "The Impact of the Scrolls on Biblical Studies," and Harold P. Scanlin's “Text, Truth and Tradition: The Public's View of the Bible in the Light of the Dead Sea Scrolls." "This specific theme, the significance of the scrolls for Biblical Studies, is something we shall return to later.

One final publication that should certainly be mentioned is issue 12.1 of Dead Sea Discoveries, edited by Maxine L. Grossman and Catherine M. Murphy and titled The Dead Sea Scrolls in the Popular Imagination. This incredible collection of articles is the result of a special session held at the SBL Annual Meeting in Toronto in 2002, dedicated to the analysis of popular interest in the scrolls. ${ }^{15}$ All of the contributions examine, from diverse angles, the public's fascination with the scrolls, their status as "pop phenomenon," and, above all, the complex four-way relationship between scrolls, media, academics, and the public. ${ }^{16}$ The dynamics involved in this intricate (often tense) relationship, are key to understanding the multifaceted reception of the scrolls within both the academic and popular spheres, as well as the interaction between the two.

${ }^{14}$ George J. Brooke, "The Qumran Scrolls and the Demise of the Distinction Between Higher and Lower Criticism," in New Directions in Qumran Studies (ed. J. G. Campbell, W. J. Lyons, and L. K. Pietersen; LSTS 52; London: Continuum, 2005), 26-42; Stephen C. Daley, "Textual Influence of the Qumran Scrolls on English Bible Versions," in The Bible as Book: The Hebrew Bible and the Judaean Desert Discoveries (ed. E. D. Herbert and E. Tov; London: The British Library, 2002), 253-87; James A. Sanders, "The Impact of the Scrolls on Biblical Studies," in The Provo International Conference on the Dead Sea Scrolls (ed. D. W. Parry and E. Ulrich; Leiden: Brill, 1999), 47-57; Harold P. Scanlin, "Text, Truth and Tradition: The Public's View of the Bible in the Light of the Dead Sea Scrolls," in The Bible as Book: The Hebrew Bible and the Judaean Desert Discoveries (ed. E. D. Herbert and E. Tov; London: The British Library, 2002), 289-99.

15 See Maxine L. Grossman and Catherine M. Murphy, "Introduction: The Dead Sea Scrolls in the Popular Imagination,” DSD 12.1 (2005): 1-5.

${ }^{16}$ Jaqueline S. du Toit and Jason Kalman, "Great Scott! The Dead Sea Scrolls, McGill University, and the Canadian Media," 6-23; Lawrence H. Schiffman, "Inverting Reality: The Dead Sea Scrolls in the Popular Media," 24-37; George J. Brooke, “The Scrolls in the British Media (1987-2002)," 38-51; Ruth Clements, "On the Fringe at the Center: Close Encounters between 'Popular Culture' and the Orion Center for the Study of the Dead Sea Scrolls," 52-67; Maxine L. Grossman, "Mystery or History: The Dead Sea Scrolls as Pop Phenomenon," 68-86; Jeffrey H. Mahan, "The Dead Sea Scrolls in Popular Culture: 'I Can Give You No Idea of the Contents,"” 87-94; Mark Silk, "Why the Papers Love the Scrolls," 95-100. 
Thus, the foundations have been laid for a more systematic and widespread examination of the Dead Sea Scrolls from the perspective of reception history. Whether consciously or not, and perhaps even as a result of current trends in Biblical Studies, some Qumran scholars have already begun to engage in research which leans in this direction. ${ }^{17}$ The terrain, however, remains largely unexplored. Let us therefore turn now to considerations of how the field might best move forward and make some recommendations regarding areas and methods of future investigation.

\section{Reception History and the Dead Sea Scrolls}

I would like to propose that there are three main areas or categories into which future examinations of the reception and impact of the scrolls could helpfully be divided:

a) The first of these is the reception of the scrolls within the academic sphere; their influence and impact within academia itself.

b) The second is popular reception of the scrolls; their impact within popular culture and as seen through a non-academic lens.

c) The third category, which both overlaps with and yet is quite clearly separate from the preceding two, is what we shall refer to as "knowledge transfer"; that is, the educational and informative processes which are taking place, primarily (or ostensibly) in the direction from the academic sphere to the popular sphere.

Each of these categories contains a wide diversity of sub-areas worthy of further investigation and thus numerous possible lines of enquiry. I shall simply attempt here to highlight, in each case, a number of key areas which, in terms of advancing the field, seem either most pressing or potentially the most rewarding.

\section{a) Academic Reception of the Scrolls}

Our first category, the academic reception of the scrolls, is in itself a vast topic, taking as its focus, not the scrolls themselves, but our own responses to them

\footnotetext{
${ }^{17}$ Note, for instance, "The Dead Sea Scrolls and Contemporary Culture: Celebrating 60 Years of Discovery," a conference held in Jerusalem, 6-8 July 2008. The proceedings of this meeting have recently been published: Adolfo D. Roitman, Lawrence H. Schiffman, and Shani Tzoref, eds., The Dead Sea Scrolls and Contemporary Culture: Proceedings of the International Conference held at the Israel Museum, Jerusalem (July 6-8, 2008) (STDJ 93; Leiden: Brill, 2011).
} 
and the ways in which they have influenced and impacted upon academia. For the time being, however, I would like to draw attention to just three main sub-areas where useful work could be done: (i) analysis of the internal processes of scrolls scholarship; (ii) influence upon and relationship with Biblical Studies; and (iii) aspects of gender in relation to scrolls scholarship and textual interpretation.

\section{i) The Internal Processes of Scrolls Scholarship}

The first of these, analysis of the internal processes of scrolls scholarship, would include, for instance, the aforementioned work done by Edna UllmannMargalit; "research about scrolls research."18 In this context, Robert A. Kugler states that "[t]he Qumran Scrolls have engendered their own modern community," while Ullmann-Margalit likewise notes "the eerie yet pervasive feeling that in dealing with the Dead Sea Scrolls one is facing a sectarian phenomenon not only as regards the authors of the scrolls, but as regards their researchers as well."19 This modern scrolls community is, from the perspective of reception history, just as deserving of examination and scrutiny as the ancient one responsible for the texts.

In particular, questions can be asked about the (often unconscious) influences at work within scrolls scholarship. What are the origins of our various ideas about the scrolls and how have they developed? Can biases or assumptive arguments be found in our approaches to, and interpretations of, the scrolls over the past sixty years, and, if yes, can we determine whether these have influenced (and had a knock-on effect for) subsequent scholarship? In other words, might some of our perceptions be based on faulty reasoning? How exactly have ideas been transmitted and developed through sixty years of publications, and can these processes be independently evaluated? How do the internal workings of scrolls scholarship compare with and conform to principles of scientific theory formation in general $?^{20}$

\footnotetext{
${ }^{18}$ See n. 8 above. Note also the following forthcoming edited volume: Devorah Dimant and Annette Steudel, eds., The History of Qumran Research (STDJ; Leiden: Brill, forthcoming).

${ }^{19}$ Robert A. Kugler, "Whose Scripture? Whose Community? Reflections on the Dead Sea Scrolls Then and Now, By Way of Aramaic Levi," DSD 15.1 (2008): 5-23 (6); Ullmann-Margalit, "Spotlight on Scroll Scholars," 64.

${ }^{20}$ With regard to this latter point, the groundwork for such an investigation has already been laid by Edna Ullmann-Margalit (see nn. 8 and 9 above).
} 
To give a specific example, we might question to what extent the early or formative years of scrolls scholarship have shaped subsequent interpretation. The very fact that the discovery (not to mention publication) of the scrolls took place over a prolonged period, may also play a role. In view of that, how far might the initial Cave 1 discoveries, for instance, be said to have influenced and colored (perhaps even distorted) our interpretation of the later discoveries in Caves 2-11? Early on, a "perceived" Qumran history and identity was derived from the Cave 1 texts alone, swiftly gaining widespread acceptance among the first scrolls scholars. Since all subsequent evidence was considered with this "received" wisdom already in mind, the potential is there at least for unbalanced interpretation and a tendency towards the incorporation of such evidence within the existing model. ${ }^{21}$ As Moshe J. Bernstein asks:

[W] hat would have been the result had the Qumran texts been discovered and published in a different order than they were? ... [M] any of the presuppositions, the touchstones which have governed our research ..., would likely have been quite different. The significance of the sequence of publication of the Qumran documents is a phenomenon which, I believe, has generally been overlooked. ${ }^{22}$

In short, an examination of the processes by which we have arrived at our historical reconstructions and syntheses, and an evaluation of our own influences and preconceptions, is vital to both a better understanding of how the scrolls have been received and appropriated by the academic community, and to a more nuanced view of the scrolls themselves.

\section{ii) Biblical Studies}

The second of our sub-areas within the more general category of academic reception concerns the influence of the scrolls upon, and their relationship with, Biblical Studies. We have already seen how a number of scholars have begun to

\footnotetext{
${ }^{21}$ A point discussed at the Sixth Meeting of the IOQS, in response to the following unpublished paper: Matthew A. Collins, “'Perceived' Qumran History and the Legacy of the Cave 1 Discoveries” (paper presented at the IOQS meeting, Ljubljana, Slovenia, 18 July 2007).

${ }^{22}$ Moshe J. Bernstein, "Introductory Formulas for Citation and Re-Citation of Biblical Verses in the Qumran Pesharim: Observations on a Pesher Technique," DSD 1.1 (1994): 30-70 (30). See also, Norman Golb, "Khirbet Qumran and the Manuscripts of the Judaean Wilderness: Observations on the Logic of their Investigation,” JNES 49.2 (1990): 103-14 (esp. 109-10).
} 
address the question of how our readings of (and approaches to) the Bible have been affected by the scrolls. ${ }^{23}$ At a textual level, we may note changes and additions to our versions of the biblical texts themselves, made in the light of readings preserved at Qumran (for instance, the well-known example of the NRSV's decision to include, at the end of 1 Sam 10, a passage missing from the Masoretic Text but preserved in $\left.4 \mathrm{QSam}^{\mathrm{a}}\right){ }^{24} \mathrm{We}$ may also identify more general trends, such as reconsideration of topics like canon formation, scriptural authority, and textual criticism. ${ }^{25}$

However, broader questions may also be posed, such as how has the field of Biblical Studies reacted generally to the discovery of the scrolls? Aside from the scrolls scholars themselves, how far have other academics (in this instance, biblical scholars) utilized the evidence of the scrolls within their own field? ${ }^{26}$ Related to this, one might even ask to what extent Qumran Studies has both integrated itself with and isolated itself from other disciplines? Does its very nature as a separately designated field of study hamper its proper contextualization within the wider world of Biblical and Jewish Studies? ${ }^{27}$ In fact, by speaking of "scrolls scholars" and "scrolls

\footnotetext{
${ }^{23}$ See n. 14 above.

${ }^{24}$ See, e.g., Eugene C. Ulrich, The Dead Sea Scrolls and the Origins of the Bible (Grand Rapids: Eerdmans, 1999), 184-201.
}

${ }^{25}$ For instance, Jonathan G. Campbell, “4QMMT ${ }^{\mathrm{d}}$ and the Tripartite Canon,” JJS 51 (2000): 181-90; Jonathan G. Campbell, “'Rewritten Bible' and 'Parabiblical Texts': A Terminological and Ideological Critique," in New Directions in Qumran Studies (ed. J. G. Campbell, W. J. Lyons, and L. K. Pietersen; LSTS 52; London: Continuum, 2005), 43-68; Shemaryahu Talmon, "The Crystallization of the "Canon of Hebrew Scriptures' in the Light of Biblical Scrolls from Qumran," in The Bible as Book: The Hebrew Bible and the Judaean Desert Discoveries (ed. E. D. Herbert and E. Tov; London: The British Library, 2002), 5-20; Arie van der Kooij, "The Textual Criticism of the Hebrew Bible before and after the Qumran Discoveries," in The Bible as Book: The Hebrew Bible and the Judaean Desert Discoveries (ed. E. D. Herbert and E. Tov; London: The British Library, 2002), 167-77. Also, White Crawford, "The Dead Sea Scrolls," 84-85.

${ }^{26}$ At the fiftieth anniversary of the discovery of the scrolls, Hartmut Stegemann ("Qumran Challenges," 947) noted that: "there are still very few Hebrew Bible scholars who have begun to include the new Qumran evidence into their framework of describing the interrelationship between the different biblical traditions, sources, books, and their final redactions. Most Hebrew Bible scholars still regard the new Qumran evidence as basically 'post-canonical' and of no special interest for them.”

${ }^{27}$ On the impact of the scrolls upon Judaism and Jewish Studies, see for instance: Richard A. Freund, "How the Dead Sea Scrolls Influenced Reform Judaism," American Jewish Archives Journal 61.1 
scholarship" at all, are we in effect de-contextualizing this particular body of evidence from the wider historical and textual world to which it belongs? Ultimately, how have the scrolls informed our reading of the Bible and, crucially, to what extent have these insights been carried over into related fields, such as Biblical Studies?

\section{iii) Gender Aspects}

While there are obvious overlaps with examinations of the internal processes of scrolls scholarship, the question of gender in relation to the reception of the scrolls is one that is perhaps also worth briefly highlighting here as a separate potentially fruitful avenue of enquiry. Although various studies have addressed both the presence and absence of women in the Qumran textual and archaeological record, from the perspective of reception history it would be more interesting to ask how significant gender issues have been within scrolls scholarship itself. ${ }^{28}$ For instance, might the allmale (predominantly clerical ${ }^{29}$ nature of the early editorial team have in any way influenced their interpretation of the evidence? To give but one example, might ordained men have been predisposed to more readily favor evidence (textual and/or archaeological) supporting the notion of an all-male "monastic" community over that which problematized this view $?^{30}$ Would the scholarship and interpretations of an

(2009): 115-43; Lawrence H. Schiffman, "Halakhah and History: The Contribution of the Dead Sea Scrolls to Recent Scholarship," in id., Qumran and Jerusalem: Studies in the Dead Sea Scrolls and the History of Judaism (Grand Rapids: Eerdmans, 2010), 63-78.

${ }^{28}$ For more traditional examinations of women in the scrolls, see initially: Eileen M. Schuller, "Women in the Dead Sea Scrolls," in The Dead Sea Scrolls After Fifty Years: A Comprehensive Assessment (vol. 2; ed. P. W. Flint and J. C. VanderKam; Leiden: Brill, 1999), 117-44; Cecilia Wassen, Women in the Damascus Document (Atlanta: Society of Biblical Literature, 2005); Sidnie White Crawford, "Not According to Rule: Women, the Dead Sea Scrolls and Qumran", in Emanuel: Studies in Hebrew Bible, Septuagint and Dead Sea Scrolls in Honor of Emanuel Tov (ed. S. M. Paul et al.; Leiden: Brill, 2003), $127-50$.

${ }^{29}$ Of the original editorial team, Roland de Vaux, Dominique Barthélemy, Pierre Benoit, Jozef T. Milik, Jean Starcky, Patrick W. Skehan, and Maurice Baillet were all ordained. See further, Fields, The Dead Sea Scrolls: A Full History, 1:191-239.

${ }^{30}$ In this context, Joan E. Taylor notes: "All of our interpretations of data are to some degree conditioned by our expectations and preconceptions and no one is exempt from the tendency to present evidence in a somewhat biased fashion, no matter how hard we may strive for impartiality and 
initial mixed-gender editorial team have looked any different? Furthermore, to what degree, if any, has the marginalization of female scholars in the first forty years of "official" scholarship contributed to the marginalization of women within readings of the texts themselves? ${ }^{31}$ Questions such as these may pave the way for an examination of our own responses to (and appropriation of) the scrolls through a lens sensitive to the potential role of gender issues in scholarship.

\section{b) Popular Reception of the Scrolls}

Leaving behind academic reception of the scrolls, our second major category into which future investigations might fall concerns the reception of the scrolls within the popular sphere. Here, a major topic for examination would be the ways in which public perceptions of the scrolls have differed from academic ones. As mentioned at the start of this paper, within popular culture the Dead Sea Scrolls seem to have become symbolic of mysterious and ancient wisdom, and frequently associated with conspiracy and controversial hidden truths. In this context we might highlight the revealing title of a public lecture given by Jason Kalman of Hebrew Union College at the Canadian Museum of Civilization in 2004: "Bigfoot, Elvis, and Aliens: The Canadian Media and the Dead Sea Scrolls." ${ }^{32}$ It could well be argued that, for a proportion of the public at least, the scrolls occupy this category far more readily than that of sober textual and historical criticism. Indeed, the opening chapter of Timothy H. Lim's The Dead Sea Scrolls: A Very Short Introduction, titled "The Dead Sea Scrolls as Cultural Icon," begins with the astute observation: "Many people have heard of the Dead Sea Scrolls, but few know what they are." ${ }^{33}$ Accordingly, Maxine L. Grossman describes the scrolls as "open signifiers": "a category whose basic frame

objectivity" (in “The Cemeteries of Khirbet Qumran and Women's Presence at the Site," DSD 6.3 [1999]: 285-323 [322]).

${ }^{31}$ I am very grateful here to W. John Lyons for his suggestion of a Gender Studies approach to scrolls scholarship as a potentially fruitful direction from the perspective of reception history.

32 March 25, 2004 at the Canadian Museum of Civilization in Gatineau, Quebec (see further: www.civilization.ca/cmc/media/press-releases/year-2004/bigfoot-elvis-and-aliens-the-canadian-mediaand-the-dead-sea-scrolls).

33 Timothy H. Lim, The Dead Sea Scrolls: A Very Short Introduction (Oxford: Oxford University Press, 2005), 1. 
is recognizable ('ancient documents found in the region of the Dead Sea') but whose specific content is not." 34 That the mythic status of the scrolls has, in the popular sphere, overshadowed their reality is in itself an intriguing state of affairs, and one worthy of further study.

An evaluation of this wider impact of the Dead Sea Scrolls, noting in particular the manner and extent of their permeation into popular culture, would be a task that is in equal parts both difficult and rewarding. Their employment within popular culture is the very window through which public perceptions of them might best be understood. Given this, we may identify a number of key areas or mediums which could be explored; for instance, the scrolls in:

i) Literature (e.g., their portrayal in dozens of novels such as Joel C. Rosenberg's political thriller The Copper Scroll, Philip K. Dick's The Transmigration of Timothy Archer, or Eliette Abécassis' The Qumran Mystery [the first part of her trilogy of Qumran thrillers]); ${ }^{35}$

ii) Film and television (e.g., the Japanese anime series Neon Genesis Evangelion [where the scrolls play a major role and are said to contain prophecies of a coming apocalypse], the Italian film Gli amici di Gesù - Tommaso [which includes portrayal of Qumran and its inhabitants], or episode 5, season 3 of Lois and Clark: The New Adventures of Superman [where Superman discovers a Dead Sea Scroll and employs a psychic in order to decipher it!]); ${ }^{36}$

\footnotetext{
${ }^{34}$ Grossman, "Mystery or History," 76.

35 Joel C. Rosenberg, The Copper Scroll (Tyndale House, 2006); Philip K. Dick, The Transmigration of Timothy Archer (Timescape, 1982); Eliette Abécassis, Qumran (Librairie Générale Française, 1996; English translation: The Qumran Mystery [Orion Books, 1998]). For the scrolls in works of fiction, see further: John Kissinger, “Archaeology as 'Wild Magic': The Dead Sea Scrolls in Popular Fiction,” Journal of American Culture 21.3 (1998): 75-81; Brenda L. Segal, “Holding Fiction's Mirror to the Dead Sea Scrolls," in The Dead Sea Scrolls: Fifty Years After Their Discovery, 1947-1997 (ed. L. H. Schiffman, E. Tov, and J. C. VanderKam; Jerusalem: Israel Exploration Society, 2000), 906-12; Brenda L. Segal, “The Copper Scroll: Novel Approaches,” in Copper Scroll Studies (ed. G. J. Brooke and P. R. Davies; JSPSup 40; London: Sheffield Academic Press, 2002), 271-75. Note also, Simon Armitage, The Dead Sea Poems (Faber and Faber, 1995).

${ }^{36}$ Neon Genesis Evangelion (dir. H. Anno; 1995-1996); Gli amici di Gesù - Tommaso (dir. R. Mertes; 2001); "Just Say Noah" (episode 5, season 3 of Lois and Clark: The New Adventures of Superman; dir. D. Jackson; aired October 22, 1995 ; see further:
} http://www.zen134237.zen.co.uk/Lois_and_Clark/Lois_and_Clark_3x05_-_Just_Say_Noah.txt). 
iii) Music (e.g., the 1991 album The Dead Sea Scrolls by The Bollock Brothers, Kim Cunio's 2000 album Music of the Dead Sea Scrolls [setting the texts of certain scrolls to musical accompaniment], or the Manic Street Preachers song "So Why So Sad," from their 2001 album Know Your Enemy [whose chorus includes the line "Searchin' for the Dead Sea Scrolls, so why, so why so sad?'] $) ;^{37}$

iv) Art (e.g., Shraga Weil's illustrations in the 1966 Limited Editions Club edition of Geza Vermes' The Dead Sea Scrolls, Joshua Neustein's 2009-10 exhibition of works at the Royal Ontario Museum in Toronto [titled "Margins: Contemporary Art Unraveling the Dead Sea Scrolls"], or the scrolls-related artwork of Lika Tov [who utilizes the distinct shapes of the fragments themselves as a source of inspiration]). ${ }^{38}$

Each of these mediums affords us an important glimpse of how the scrolls have been received and interpreted within the popular sphere. What is needed, however, is not only documentation of such occurrences but critical evaluation of the extent to which they may be said to reflect and/or influence public perceptions of the scrolls. Attention must also be paid to how and why these differ from academic perceptions of the scrolls. What is the nature of the conceptual space occupied by the scrolls in the public consciousness and by what processes is it maintained?

\section{c) Knowledge Transfer}

37 The Bollock Brothers, The Dead Sea Scrolls (CD; SPV Records, 1991; remastered and re-released, MBC Records, 2001); Kim Cunio, Music of the Dead Sea Scrolls (CD; Lotus Foot, 2000); Manic Street Preachers, Know Your Enemy (CD; Epic Records, 2001).

${ }^{38}$ Geza Vermes, The Dead Sea Scrolls (illustrated by Shraga Weil; Limited Editions Club; Westerham Press: Westerham, 1966); see further: http://www.safrai.com/liste.php?artist=11. Joshua Neustein, "Margins: Contemporary Art Unraveling the Dead Sea Scrolls" (art exhibition; Royal Ontario Museum, Toronto, Canada, June 27, 2009 - March 28, 2010; see further: www.rom.on.ca/exhibitions/special/margins.php and http://heritagekey.com/blogs/owenjarus/interview-artist-joshua-neustein-responding-dead-sea-scrolls). Lika Tov, "Some Dead Sea Scrolls Fragments as a Source of Inspiration for My Art," in Qumran and the Bible: Studying the Jewish and Christian Scriptures in Light of the Dead Sea Scrolls (ed. N. David and A. Lange; Leuven: Peeters, 2010), 29-41; see further: http://www.likatov.info/. 
Our third (and final) major category, "knowledge transfer," concerns the points of interaction between "academic" and "popular" reception; in particular, as we have already noted, the educational and informative processes taking place primarily (or ostensibly) in the direction from the academic sphere to the popular sphere. This overlaps somewhat with both of our preceding two categories and yet is also clearly distinct. Adolfo D. Roitman, Curator of the Dead Sea Scrolls (Shrine of the Book, Jerusalem), has said that, generally speaking, the public "know the scrolls are important, but they don't know why." 39 The same observation can be made upon examining some of the occurrences of the scrolls in popular reception; they are clearly regarded as significant, though there is often a lack of informed knowledge about what that significance is. The gap between academic scholarship and popular understandings of the scrolls is a void which is in continual need of being rebridged. ${ }^{40}$ Indeed, Roitman suggests that "it has become truly necessary to start developing systematically a new field of expertise, with its own theory and methods: the teaching and popularization of the Dead Sea Scrolls." ${ }^{41}$ Certainly any comprehensive examination of the reception history of the scrolls needs to address not only "academic" and "popular" reception, but also the attempts made to bridge the gap between the two; that is to say, the educational and informative processes of socalled "knowledge transfer." By way of example, let us again highlight three key areas which may be worthy of further investigation.

\section{i) Exhibitions}

The first of these concerns public exhibitions of the scrolls. Here, the choice of materials displayed and the manner of their presentation (for instance, the accompanying descriptions and overall narrative) are typically the product of scrolls

${ }^{39}$ Quoted in Jack Meinhardt, "Roitman Appointed Curator at Shrine of the Book," BAR 21.1 (1995): 20.

${ }^{40}$ See initially, Mahan, "The Dead Sea Scrolls.” Note further, Jaqueline S. du Toit and Jason Kalman, “Albright's Legacy? Homogeneity in the Introduction of the Dead Sea Scrolls to the Public," JNSL 36.2 (2010): 23-48.

41 Adolfo D. Roitman, "The Quest for New Strategies in Teaching and Popularizing the Dead Sea Scrolls," in The Dead Sea Scrolls and Contemporary Culture: Proceedings of the International Conference held at the Israel Museum, Jerusalem (July 6-8, 2008) (ed. A. D. Roitman, L. H. Schiffman, and S. Tzoref; STDJ 93; Leiden: Brill, 2011), 719-30 (722). 
academics and those responsible for their preservation, but the intended audience consists primarily of non-specialists (i.e., the general public). In other words, exhibitions constitute, for the most part, attempts to take scholarly responses to the scrolls and transfer these to the public sphere; academic reception as "officially" mediated to the public. ${ }^{42}$

This process raises its own questions. Against the backdrop of scholarly disagreement and diversity, each exhibition must select information to include and information to omit; what is the significance (and what are the ramifications) of the choice of a particular narrative, subsequently presented to the (unsuspecting) public with the air of authority? ${ }^{43}$ How have issues of consensus and dispute, unity and diversity, been dealt with? As an educational medium, should exhibitions (and their catalogs) embrace diversity and aim for inclusiveness (presenting the public with a fully representative range of views, but thereby perhaps leaving many questions ultimately unanswered and the visitor potentially perplexed and uncertain about what they've just seen) or attempt to present a strong unilateral narrative (focusing on points of consensus and underplaying dispute in order to deliver a clearer educational message, but thereby privileging one side of the story and potentially not telling the visitor "the whole truth")? The nature and purpose of the medium, as well as the intended audience, are all factors to be taken into consideration. We might further examine how these "official" presentations of the scrolls have differed, both

\footnotetext{
${ }^{42}$ See initially, Adolfo D. Roitman, "Exhibiting the Dead Sea Scrolls: Some Historical and Theoretical Considerations," in Archaeology and Society in the 21st Century: The Dead Sea Scrolls and Other Case Studies (ed. N. A. Silberman and E. S. Frerichs; Jerusalem: Israel Exploration Society, 2001), $41-$ 66.
}

${ }^{43}$ While admittedly pursuing his own agenda, Norman Golb has addressed some of the issues related to "authoritative" presentations of the scrolls, in "The Dead Sea Scrolls and the Ethics of Museology," Aspen Institute Quarterly 6.2 (1994): 79-98; as well as in numerous online articles (available here: http://oi.uchicago.edu/research/projects/scr/): “As the Scrolls Arrive in Chicago...” (2000; rev. July 30, 2007); "The Current Controversy over the Dead Sea Scrolls, with Special Reference to the Exhibition at the Field Museum of Chicago" (2000; rev. July 30, 2007); “The Dead Sea Scrolls at Seattle's Pacific Science Center" (rev. December 19, 2006); "Fact and Fiction in Current Exhibitions of the Dead Sea Scrolls - A Critical Notebook for Viewers" (June 1, 2007); “The Dead Sea Scrolls as Treated in a Recently Published Catalogue" (October 22, 2007); "The Current New York Exhibition of the Dead Sea Scrolls: An Appraisal” (November 17, 2008); “On the Current Exhibit of Dead Sea Scrolls at the Milwaukee Public Museum” (2010). 
chronologically (across the last sixty years) and regionally (across the globe). Can trends or agendas be discerned? In essence, might examination of the differing ways in which the scrolls have been represented help us to better understand the differing ways in which they have been appropriated and understood?

\section{ii) Documentaries}

In similar fashion, we might turn our attention to television documentaries about the scrolls. Here too, "official" views are conveyed to the public with an air of authority, and the same questions asked above may likewise be posed here. In this case, however, the selection of scholars interviewed and the range of views expressed tends to be in the hands of the production company, whose own agenda drives the program. This makes it much harder for an unsuspecting public to discern between mainstream theories and fringe ideas, since both can be presented as equally authoritative. Indeed, such documentaries may even promote a fringe scholar or theory into the limelight, casting more mainstream academics into the role of conservative and unenlightened sideliners; a process which Lawrence H. Schiffman describes as "inverting reality." 44 It falls to the viewer to somehow distinguish between those documentaries which accurately reflect the current debate within the academic community, and those of a more sensationalist nature. Given the authoritative tone of both program and narrator in each case (as well, of course, as the process of selection and omission of information in the interest of a "clean" storyline), ${ }^{45}$ such a task is understandably difficult (if not downright impossible) for the uninitiated layperson. Since such documentaries are, for the majority of the general public, one of the most accessible forms of "authoritative" information about the scrolls, these intrinsic problems may in turn result in public perceptions of the scrolls being similarly inverted and skewed by the more sensationalist of these presentations; a process that is perhaps reflected in some aspects of the reception of the scrolls in popular culture. How might we evaluate the impact of such "pseudoacademic" instances of knowledge transfer upon the wider reception of the scrolls?

\footnotetext{
${ }^{44}$ Schiffman, "Inverting Reality." See also Brooke, "The Scrolls in the British Media," and Grossman, "Mystery or History."

${ }^{45}$ As Brooke notes, "the multi-faceted truth would be hard to tell" ("The Scrolls in the British Media," 40).
} 
And to what extent are skewed or sensationalist presentations successfully combatted by those providing a more balanced picture? Ultimately, how helpful are television documentaries (from an academic standpoint) as an educational tool for (i) raising the profile of the Dead Sea Scrolls and/or (ii) relaying accurate and reliable information to the public, and what role have they played in the permeation of the scrolls into popular culture?

\section{iii) Newspapers}

Newspaper articles (and indeed the news media generally) constitute a third medium worthy of examination. Here, many of the issues related to the presentation of the scrolls in television documentaries are once again in play, especially since the process is even further removed from academic control. The nature and tone of the medium conveys authority and neutrality, but the actual content is driven more by the need for "a good story." 46 Indeed, the desire to retain neutrality (or at least a semblance thereof) can itself be the cause of skewed presentations of both the scrolls and their scholarship. Maxine L. Grossman notes, in a short piece for the November 2006 Orion Center Newsletter, that newspaper journalism judges itself to be "fair" when "both sides" are presented equally. She goes on to highlight the key differences between scholarly and popular discourse (in short, “As academics we don't really believe in 'both,' and we have a very different definition of 'fair'"), and observes that forcing the complex myriad of theories about the scrolls into an artificial dualistic framework (generally "mainstream versus new challenger") is both misrepresentative and misleading, especially when a far-fetched fringe theory is, in the name of neutrality and fairness, elevated to the role of equally legitimate contender. ${ }^{47}$ As a result, we may question the suitability of the media (from an academic perspective) as a reliable means of knowledge transfer when it comes to the scrolls. Its motivation and agenda are considerably removed from those of academic scholarship, thus generating a "new" dynamic in the reception history.

\footnotetext{
${ }^{46}$ See initially, Brooke, "The Scrolls in the British Media," and Schiffman, "Inverting Reality." Also, Mahan, "The Dead Sea Scrolls in Popular Culture," and Silk, "Why the Papers Love the Scrolls."

${ }^{47}$ Maxine L. Grossman, “'Both Sides' of the Story: When Scrolls Scholars and the Media Don't Quite Communicate," Orion Center Newsletter (November 2006). On differing "discursive realms," see further, Grossman, "Mystery or History."
} 
Mark Silk acknowledges that, compared with documentaries, newspapers "require that a higher hurdle of novelty be jumped" (i.e., a new development or new angle [whether real, perceived, or invented]), but also points out that "the sensational is not ipso facto bad." ${ }^{48}$ That is to say, it is the very sensationalism and intrigue attached to public perceptions of the scrolls, which ensures and maintains their high profile in popular culture. This is what transforms them in the public eye from the dusty, boring old manuscripts they might potentially have been viewed as, into the scandalous, mysterious (even dangerous), secret texts they are so widely perceived to be. While often a source of irritation for scholars keen to educate the public about the true significance of the scrolls, the flipside of the coin is that it is precisely because of these popular misconceptions (not in spite of them) that we are guaranteed a ready and eager audience outside of the academic sphere. This is why the public flock to scrolls exhibitions, are fascinated by scrolls documentaries, and are intrigued by scrolls stories in the media - and ironically it is exactly this which provides us with such a rare opportunity to transfer our academic research and interests into the popular sphere and the public consciousness. ${ }^{49}$

Exhibitions, documentaries, and newspaper stories constitute something different again from both the academic reception of the scrolls which they purport to reflect and the popular reception of the scrolls which they feed and indeed shape. It is in this context, as important mediums for "knowledge transfer" and sources of "mediated reception," that they deserve to be more extensively studied.

\section{Conclusion}

As "reception history" continues to play an ever more important role within Biblical Studies, it is increasingly apparent (as demonstrated in a number of recent studies highlighted here) that the same perspective might successfully be applied to Qumran Studies, resulting in important and timely examinations of the modern reception, influence, and impact of the Dead Sea Scrolls. The intricate history of scrolls scholarship, coupled with the intense public fascination with them, not only lends itself to such an approach, but actively invites it. While certainly not intending

\footnotetext{
${ }^{48}$ Silk, "Why the Papers Love the Scrolls," 95-96.

49 On the educational dimension and the development of strategies for communicating with and teaching the public about the scrolls, see Roitman, "The Quest for New Strategies" (esp. 726-30).
} 
to be exhaustive, this article has attempted to outline some possible directions for future investigation, identifying academic reception of the scrolls (that is, the ways in which they have been used by, influenced, and impacted upon academia), popular reception of the scrolls (their impact within popular culture, including literature, film and television, music, and art), and mediums of "knowledge transfer" (analysis of the points of interaction between "academic" and "popular" reception, and evaluation of the educational and informative processes taking place in attempts to bridge the gap between the two) as three main areas or categories into which such examinations could helpfully be divided. The boundaries between these three areas are far from rigid, but they may nevertheless prove a useful starting point for future exploits.

Roitman notes that "[s]ince the discovery of the Dead Sea Scrolls, the intellectual efforts of scholars have been devoted to understanding the data in their original historical context. Until now, our attention was directed towards the past." As a different, more reflective type of approach to the topic, reception history perspectives promise not only a rich and fertile avenue for future investigation, but the possibility of thereby uncovering valuable insights into our own continuing complex relationship with the scrolls.

\footnotetext{
${ }^{50}$ Roitman, “The Quest for New Strategies,” 730.
} 